\title{
Técnica de auto-spreader en rinoplastía primaria
}

\section{Auto spreader technics in primary rhinoplasty}

\author{
Alfredo Santamaría C, Sahba Sedaghat N.
}

La reducción de giba en rinoplastía primaria es una de las correcciones estéticas más solicitadas y por lo tanto de las frecuentemente realizadas. La resección de la porción cartilaginosa de la giba pone en riesgo la mantención del ángulo de la válvula $\left(10^{\underline{a}}\right.$ a 15a), por la pérdida de la porción horizontal de los cartílagos laterales superiores (CLS) que se fusionan con el cartílago cuadrangular (CO), existiendo además la posibilidad que con la posterior retracción de los tejidos se produzca un pinzamiento. Esto crea una típica deformidad como $\mathrm{V}$ invertida hacia los lados, en la unión ósteo-cartilaginosa del dorso.

La forma tradicional de solucionar este problema ha sido el uso de injertos de cartílago (spreader o ensanchadores) obtenidos habitualmente de tabique o pabellón auricular, que se colocan y se suturan entre el remanente de los CS y $\propto$.

La utilización de la porción horizontal del CLS, en vez de resecarlo, como colgajo de spreader nos permite ahorrar cartílago y tiempo quirúrgico ya que la maniobra de su uso es de fácil ejecución.

La técnica se puede realizar con abordaje abierto o cerrado. Una vez expuesta la giba y separado el mucopericondrio endonasal se procede a hacer un corte separando el CS del C lo más medial posible. Luego dependiendo del tamaño y ancho de la giba a resecar se secciona cuidadosamente entre $2 \mathrm{~mm}$ a $4 \mathrm{~mm}$ de la inserción de los CS a los huesos propios en la zona medial (Fgura 1).

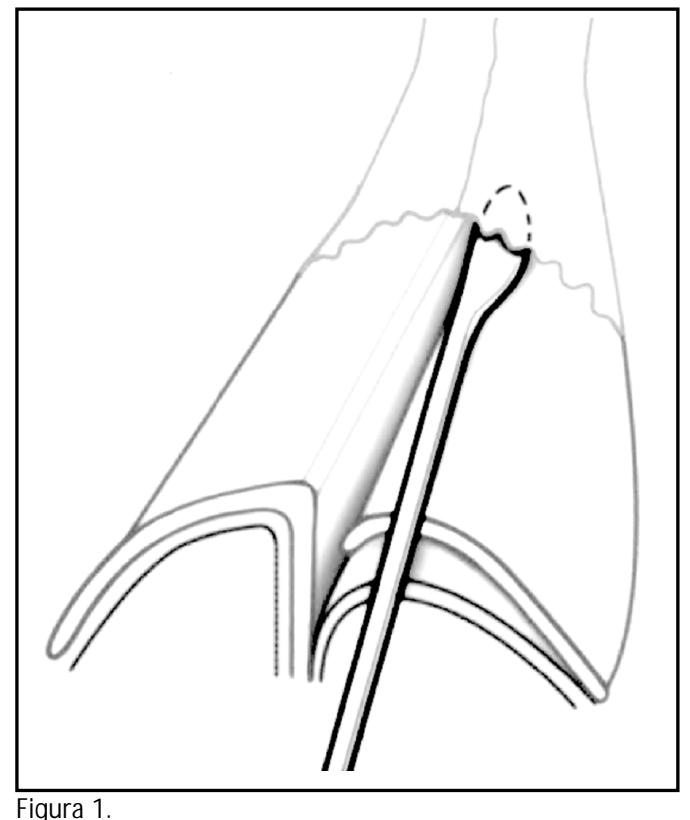

$\overline{1} \overline{1}$ Médico, Servicio ORL Hospital Guillermo Grant Benavente, Concepción. 


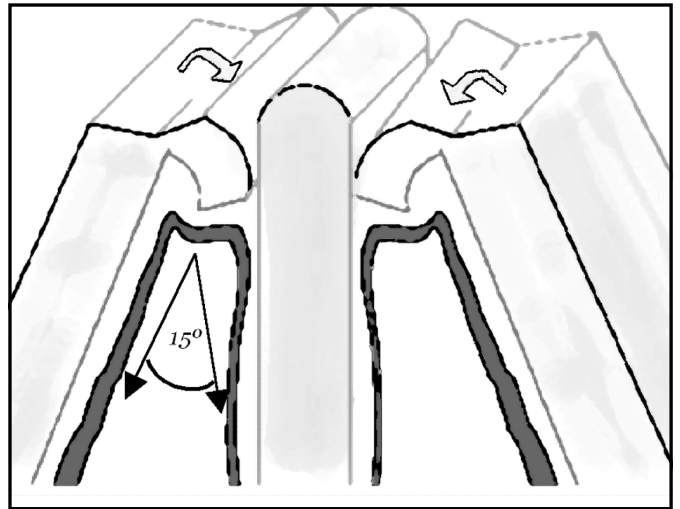

Figura 2.

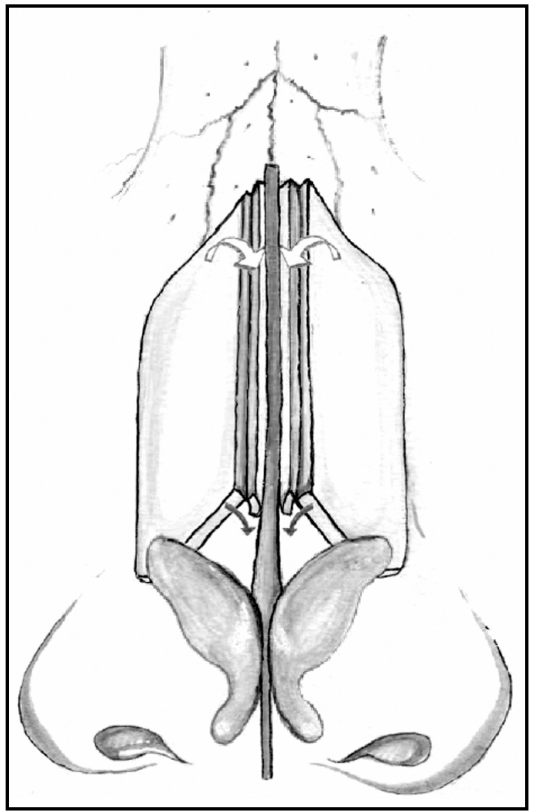

Figura 3.
Posteriormente se realiza una sección superficial (no transfixiante) del borde medial del CSS, 2 $\mathrm{mm}$ a $4 \mathrm{~mm}$ paralelo a la línea media, lo que permite rotar hacia adentro este colgajo, invaginándolo (Fguras 2 y 3). De esta manera ocupa la posición de un injerto tipo spreader.
Luego se procede a resecar la giba cortando el borde anterior sobrante del $C \mathrm{C}$ en continuidad con la giba ósea. Una vez regularizado el dorso se procede a fijar los autoinjertos con uno o dos puntos de Vicryl@ 5.0, lo cual habitualmente se hace con mucha facilidad ya que los autoinjertos se posicionan en forma casi espontánea. 